\title{
Electrosynthesized molecularly imprinted polymers for protein recognition
}

\section{Júlia Erdőssy, ${ }^{1}$ Viola Horváth, ${ }^{1 *}$ Aysu Yarman, ${ }^{2}$ Frieder W. Scheller, ${ }^{2 *}$ Róbert E. Gyurcsányi ${ }^{{ }^{*}}$}

${ }^{1}$ MTA-BME Research Group of Technical Analytical Chemistry, Szt. Gellért tér 4, H-1111 Budapest, Hungary

${ }^{2}$ Institute of Biochemistry and Biology, University of Potsdam, Karl-Liebknecht-Strasse 25-26, D-14476 Potsdam, Germany

${ }^{3}$ MTA-BME “Lendület” Chemical Nanosensors Research Group, Department of Inorganic and Analytical Chemistry Budapest University of Technology and Economics, Szent Gellért tér 4, H-1111 Budapest, Hungary

Corresponding authors: robertgy@mail.bme.hu,fschell@uni-potsdam.de,vhorvath@mail.bme.hu

Dedicated to the memory of Professor Marco Mascini. 


\section{Contents}

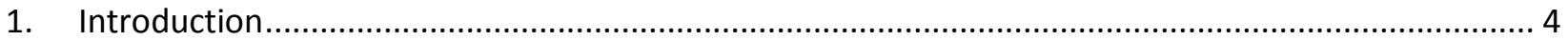

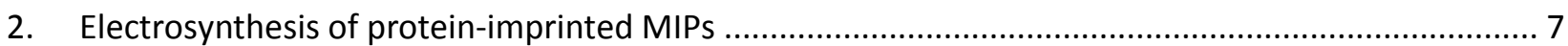

2.1. Choice of functional monomers for the electrosynthesis of protein MIPs ................................... 8

2.2. Strategies for the electrosynthesis of protein-imprinted polymers............................................ 11

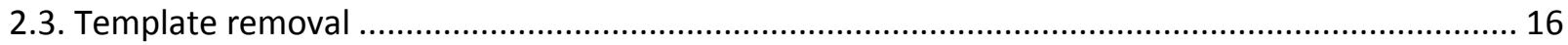

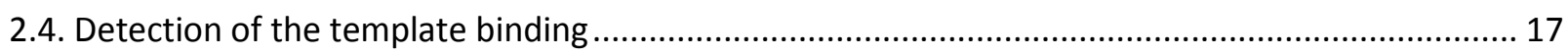

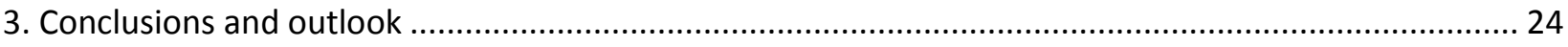

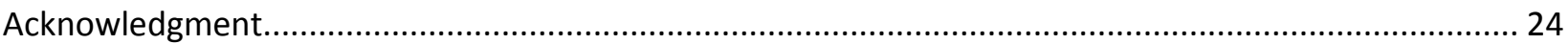

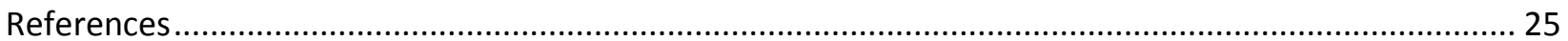




\begin{abstract}
Molecularly imprinted polymers (MIPs) for the recognition of proteins are expected to possess high affinity through the establishment of multiple interactions between the polymer matrix and the large number of functional groups of the target. However, while highly affine recognition sites need building blocks rich in complementary functionalities to their target, such units are likely to generate high levels of non-specific binding. This paradox, that nature solved by evolution for biological receptors, needs to be addressed by the implementation of new concepts in molecular imprinting of proteins. Additionally, the structural variability, large size and incompatibility with a range of monomers made the development of protein MIPs to take a slow start. While the majority of MIP preparation methods are variants of chemical polymerization, the polymerization of electroactive functional monomers emerged as a particularly advantageous approach for chemical sensing application. Electropolymerization can be performed from aqueous solutions to preserve the natural conformation of the protein templates, with high spatial resolution and electrochemical control of the polymerization process. This review compiles the latest results, identifying major trends and providing an outlook on the perspectives of electrosynthesised protein-imprinted MIPs for chemical sensing.
\end{abstract}

Keywords: molecularly imprinted polymers; proteins; surface imprinting; electropolymerization 


\section{Introduction}

Molecular imprinting is a universal concept to generate materials with "molecular memory" by performing a polymerization of suitable functional monomers in the presence of a target molecule acting as a template. The subsequent removal of the template creates recognition sites in the molecularly imprinted polymer (MIP) that can, further on, selectively rebind the target. Whilst nature has an arsenal of 20 amino acids, MIPs are typically prepared from one to four monomers. Nevertheless, this concept proved to be successful in preparing selective sorbents for compounds of small molecular weight ( $200-$ $1200 \mathrm{Da})$. However, one should confront several specific problems if the target is a macromolecular protein [1] as the classical bulk methodologies worked out for small molecular weight compounds generally fail to address the peculiarities of protein targets. The difficulties are largely attributed to the intrinsic properties of the proteins as detailed below.

- Due to their fragility irreversible conformational changes may occur during polymerization [2] and the rebinding of the native conformation to such imprinted sites is not favored.

- The large size of the proteins makes them difficult to remove from, or rebind to a highly crosslinked 3D polymeric network traditionally used in small molecule imprinting, i.e., during imprinting the macromolecules may become irreversibly entrapped in the polymeric material.

- The large number of potential interaction sites on the surface of proteins may lead to crossreactivity of the imprinted polymers and nonspecific adsorption onto bulk polymeric material.

All these difficulties caused a considerable lag in the development of protein imprinted MIPs compared to small molecule imprinting. Thus while the first research paper on a protein-imprinted MIP appeared already in 1985 [3] a steady increase in the publications can only be observed since 2005 (Figure 1). However, even in 2014 less than 1 \% of the papers published on MIPs involved protein targets. Additionally, the range of implemented protein targets is very narrow and rather restricted to templates having properties that facilitates the imprinting process. In this respect proteins with good conformational stability, and distinct physical-chemical properties (e.g. high isoelectric point, and glycosylation) were generally preferred. Such properties facilities the formation of strong and/or selective interactions such as electrostatic interaction between the positively charged proteins (e.g., lysozyme,[4] avidin[5]) and negatively charged polymers as well as between glycan moieties and aminophenyl boronic acid (APBA) monomers [6]. This is a strong indication that the field of 
macromolecular imprinting is still very much at the proof of concept level and an enhancement in selectivity and affinity is required.

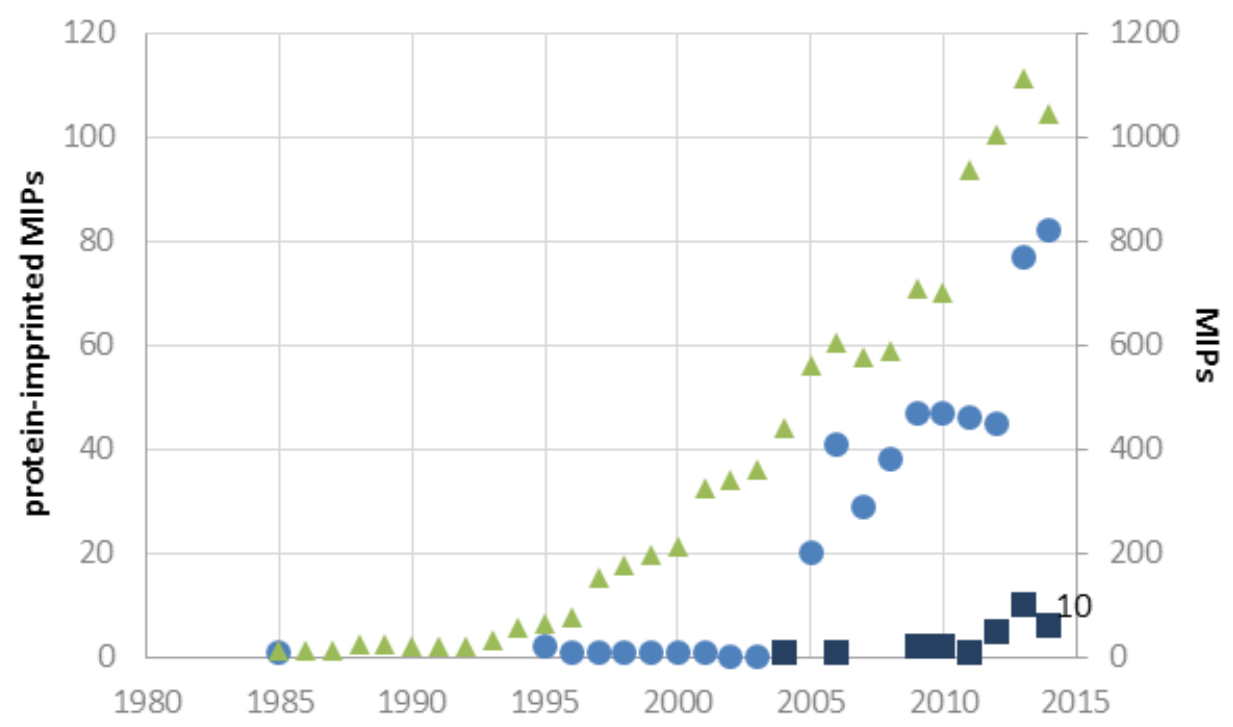

Figure 1. Number of publications on all (circles) and electrosynthesized (squares) protein-imprinted polymers and on all MIPs (triangles, right axis), until the end of 2014 (ref. www.mipdatabase.com)

Despite of the difficulties, imprinting methodologies custom tailored for protein targets are worthwhile to pursue beyond the inherent importance of protein analysis for several reasons.

- The prospects of preparing "plastic antibodies" are in general better for proteins than for small molecular weight targets as proteins are expected to generate higher affinity MIPs through the establishment of multiple interactions with their large number of functional groups.

- Molecularly imprinted polymers are expected to outperform their biological counterparts in terms of robustness and shelf-life.

- MIPs are more robust to environmental conditions and cost effective as compared to antibodies and such their application in affinity assays is resourceful.

\subsection{Main concepts to overcome the difficulties of imprinting protein targets}

During the past decade different strategies have been introduced to overcome the barriers of protein imprinting and these were reviewed in several monographies [1, 7-20]. To avoid denaturation of protein templates polymerization in aqueous media using water soluble monomers and initiators was an evident 
choice, although there have been some concerns about the deteriorating role of water on $\mathrm{H}$-bonding and dipole-dipole interactions between the functional monomers and the template.

The problem of the restricted diffusion of the bulky macromolecular template in the highly cross-linked polymer network initiated fundamentally different strategies. The first approach, using lightly crosslinked hydrogels similar to the ones used in gel electrophoresis, was initiated by Hjertén and his coworkers [21, 22]. Though not many direct evidences, the formation of highly permeable polymer structures or gels seem to not fulfil expectations with respect to the quality and stability of the imprints owing to excessive chain flexibility [20]. Another important approach is the "epitope imprinting", whereby a small, representative peptide sequence is used as the template instead of the native protein. This approach enables the implementation of non-aqueous polymerization media and complete template removal $[23,24]$. However, the rebinding of the targeted, much larger native protein may be still hindered in the MIP monolith. Therefore surface imprinting emerged as the main strategy for macromolecular imprinting. This approach restricts the formation of imprinted binding sites to the surface of a polymer or to a very thin polymer layer the thickness of which is comparable to the size of the protein template. In extreme cases proteins are captured by 2D monomolecular layers of suitable functional monomers anchored to an existing surface $[25,26]$. To maximize the binding capacity of the respective MIPs, generation of polymeric nanostructures with high area/volume ratio comes as a natural necessity to take full advantage of the surface imprinted sites. Creative methods have been devised to confine the templated sites exclusively to the polymer surface such as micro-contact imprinting techniques [4, 27-30] and sacrificial template support methods [5, 31]. Imprinted soluble nanogels, having dimensions comparable to that of protein clusters were also shown to allow facile template exchange between the polymer and the solution [32]. The so-called solid-phase synthesis approach made feasible the reproducible, controlled and large scale production of such imprinted nanogels [3335]. Interfacial polymerization on planar surfaces or supporting beads [36-38] can create ultra-thin polymer films that only partially bury the protein template without completely encapsulating it. Adherent MIP films can be polymerized in-situ by free-radical polymerization for example by spin coating [39] or drop-casting the pre-polymerization mixture onto the substrate and inducing polymerization [40]. Better control over the thickness of the sensing layer can be achieved with surface confined polymerization methods, where either the initiator $[41,42]$ or a pendant polymerizable group [43] is attached to the surface. Not only the thickness, but the area of the polymer film can be kept very small by the spatial confinement of the initiation process using light [44] or heat [45] supplied by a laser. 


\section{Electrosynthesis of protein-imprinted MIPS}

While the great majority of MIP preparation methods are variants of chemical polymerization, the electropolymerization of functional monomers emerged as particularly attractive approach to prepare MIPs for chemical sensing applications [46, 47]. This is mainly due to the effortless in-situ spatial confinement of polymer layers by electropolymerization onto the surface of a suitable electrode resulting in a proliferation of chemically-modified electrodes and electrochemical sensors that utilizes MIPs to confer selectivity $[48,49]$. Moreover, there are a number of other well-established transducers compatible with in situ electrosynthesis of MIPs such as quartz crystal resonators, surface plasmon resonance and acoustic wave sensors. Additionally, electrosynthesis is especially well-suited for the synthesis of protein-imprinted MIPs. Most of the electropolymerizable monomers can be deposited from aqueous solutions where protein molecules preserve their natural conformation. Buffers that enhance the stability of proteins can serve as supporting electrolytes during the electrochemical polymerization process. Compared to free radical polymerization initiated generally either thermally or by UV light, which may cause structural changes in the protein template, [50] electropolymerization most often requires no external initiator. The lack of initiators is also a major advantage with respect to chemically initiated polymerization. For instance the commonly used persulfate initiators, that are strong oxidizing agents, may alter the structure of proteins that are susceptible to oxidation [51]. The precise control over electrosynthesis enables the fine tuning of the polymer layer thickness, which is particularly important for the surface imprinting of proteins. Electrosynthesis can be used straightforwardly to create several nanometer thick polymer films $[52,53]$ and with the aid of sacrificial materials, micro and nanostructures with surface confined binding sites [5,54-56]. It must be noted that beside direct electrooxidation of suitable monomers the versatility of electrochemical synthesis enables surface confined polymer deposition also by electrochemically generating the "active" initiator [57] or electrochemically changing the local pH in the close vicinity of the electrode [58].

These indisputable benefits motivated us to compile the literature and evaluate the state-of-the art of electrosynthesized protein MIPs. The paper follows the work flow of MIP preparation and testing:

- Functional monomers for the electrosynthesis of protein MIPs

- Strategies for the electrosynthesis of protein-imprinted polymers

- Template removal

- Detection of the template binding 


\subsection{Functional monomers for the electrosynthesis of protein MIPS}

Electrochemical polymerization of monomers (Fig. 2) onto conducting substrates leads to the formation of either conducting or non-conducting polymer films depending on the choice of the monomer and the electropolymerization conditions. Electrically conducting polymers can be grown in thicker films, which is beneficial if the goal is to prepare complex 3D micro- or nanostructured MIPs. In contrast, the growth of insulating polymer films is self-limiting in terms of thickness, i.e., the insulating polymer layer blocks the electron transfer between the electrode and the monomer after its thickness exceeds the range of electron transfer (generally in the lower nanometer range)[59] and/or a sufficiently compact film is formed to halt the permeation of the monomer to the electrode.

The most widespread electrochemical polymerization technique for preparing protein MIPs is cyclic voltammetry. By varying the number of scan cycles and the scan rate, the thickness and the compactness of the deposited polymer film can be controlled, respectively. Too small scan rates result in tight films entrapping the template, while too large scan rates lead to a loose polymer network with low recognition ability [56],[85]. Potentiostatic deposition lacks the control over film compactness, but the film thickness can be precisely adjusted by the charge consumed during electropolymerization [48],[49]. Furthermore, the applied potential can be pulsed in order to create films with enhanced adhesion to the electrode surface [26]. The application of pulsed potential aids also the replenishment of the depleted solution layer adjacent to the electrode by the low diffusivity macromolecular template [79], [83], and thus to enhance the incorporation of the protein template into the growing polymer.

MIPs based on electrically conducting polymers primarily involve the electrochemical oxidation of pyrrole and ethylenedioxythiophene (EDOT) monomers (Fig. $2 \mathrm{f}$, g) to form protein-imprinted polypyrrole (PPy) [60] and poly(3,4-ethylenedioxythiophene) (PEDOT) [5] polymers. The removal of oxygen from the monomer solution before polymerization might be crucial for the reproducible deposition of stable conducting films as reported explicitly for PPy [61]. Polypyrrole can be additionally overoxidized by applying high potentials (e.g. $1.0 \mathrm{~V}$ vs. $\mathrm{Ag} / \mathrm{AgCl}$ ) in buffer [62] or in alkaline solutions in the presence of oxygen. Such overoxidation induces the formation of additional functionalities, e.g. carboxyl groups, with the respective polymers becoming electrically insulating. The use of PEDOT-PSS (PEDOT doped with polystyrene sulfonate) for creating different protein-imprinted nanostructures was pioneered by Gyurcsányi's group. The functional groups of this polymer offer various interactions, including hydrogen-bond, electrostatic and $\pi-\pi$ interactions and yet it has been found to show very low nonspecific adsorption of proteins [5]. These properties make PEDOT-PSS an excellent candidate for 
protein imprinting. However, electrosynthesized PEDOT MIPs have only been prepared to date for a single model template, avidin $[56,63,64]$.

Insulating polymers offer benefits in terms of preparing ultrathin films in the nanometer range as well as enabling the use of certain electrochemical detection schemes. These are based on the modulation of MIP film permeability for redox markers by protein binding or on direct electrochemical detection of proteins. In the latter respect, polyscopoletin has been introduced by Scheller's group for the selective capture of cytochrome $\mathrm{c}$ and its detection by direct electron transfer [6]. Polymerization of the natural coumarin-derivative scopoletin is robust, does not depend on deoxygenation of the monomer solution, and yields a conformal, hydrophilic film on different electrode materials [65]. Imprinting of polyscopoletin with a wide range of proteins, e.g., cytochrome c [6],[66], concanavalin A [67], and ferritin [53] has been already demonstrated. At present, the insulating MIP films prevail also in terms of binding affinity as highly conformal polyphenol nanocoatings imprinted with ferritin were reported to have affinity in the $\mathrm{fM}$ concentration region [68].

Aniline [69] and related compounds such as o-phenylenediamine [70],[71] and o-aminophenol [72] were also favored for protein imprinting since they bear functionalities that can participate in hydrogenbonding, $\pi-\pi$ and other types of interactions with the template, depending on the nature of the substituents. A monomer leading to more specific target-MIP interactions is the 3-aminophenylboronic acid, which is suited for the recognition of glycoproteins through the ability of the $-\mathrm{B}(\mathrm{OH})_{2}$ moiety to form under alkaline conditions reversible covalent bonds with vicinal diols that are commonly found in carbohydrates [73] and glycoproteins [74]. This opportunity, although well exploited in case of chemically synthesized pAPBA MIPs [75],[76], has not been employed with electropolymerized films, which have only been prepared to date for the recognition of BSA [77], lysozyme and cytochrome c [78]; all non-glycated proteins. Wang et al. imprinted pAPBA with hemoglobin, a protein that exists to a minor extent in glycated form as well, but there is no mention on the exact form of the protein [79]. Future works with electrosynthesized PAPBA MIPs for glycoprotein recognition should consider prior immobilization of the template glycoprotein, which was found essential in obtaining satisfactory selectivity against other glycoproteins [76]. Beside biocompatibility, a wide variety of functional groups and extensive knowledge about the formed polymers motivated the use of dopamine $[80,81]$ and acrylamide $[57,82]$ for protein MIPs.

In addition to the monomer and template, the pre-polymerization mixture can contain additional compounds that are also incorporated in the polymer. This option is especially obvious in case of conducting polymers where the formation of the charged polymer film requires the incorporation of 
charge compensating ions, e.g., oppositely charged small ions or polyelectrolytes from the supporting solution. However, this mechanism enables also the incorporation of nanoparticles such as polystyrene sulfonate (PSS) modified superparamagnetic nanoparticles into PEDOT microrods as shown by Ceolin et al.. Such nanoparticles may confer further functionality to the MIPs like the opportunity to handle MIP particles by an external magnetic field [55], which in turn enables their application for separation and pre-concentration.<smiles>Oc1ccccc1</smiles>

(a)<smiles>Nc1ccccc1O</smiles>

(b)<smiles>Nc1ccccc1N</smiles>

(c)<smiles>Nc1ccccc1</smiles>

(d)<smiles>COc1cc2ccc(=O)oc2cc1C</smiles>

(e)<smiles>Ic1cc[nH]c1I</smiles>

(f)<smiles>c1scc2c1OCCO2</smiles>

(g)<smiles>CCOCCOCC1(C)COc2cscc2OC1</smiles>

(i)<smiles>Nc1cccc(B(O)O)c1</smiles>

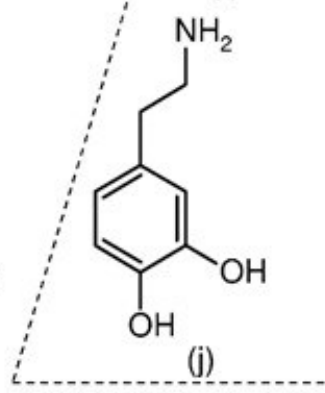

Figure 2. Representative monomers applied for the electrosynthesis of protein imprinted polymers: phenol (a), o-aminophenol (b), o-phenylenediamine (c), aniline (d), scopoletin (e), pyrrole (f), 3,4ethylenedioxythiophene (g), proDOT-COOH (h), aminophenylboronic acid (i), dopamine (j) and 2,2'bithiophene-5-carboxylic acid (k). Monomers within the dashed inset polymerize into conductive films. 


\subsection{Strategies for the electrosynthesis of protein-imprinted polymers}

Electrosynthesized MIPs have been developed for both relatively small monomeric proteins such as cytochrome c, serum albumin and troponin T, but also for oligomeric proteins like hemoglobin, avidin, lectins, and acetylcholinesterase (see Table 1 for a comprehensive compilation). The most straightforward approach, i.e. the formation of the pre-polymerization complex by simply dissolving the template in the monomer solution has already led to clear imprinting effect (Figure 3A). Karimian et al. reported that a troponin T-imprinted poly(o-phenylenediamine) film bound two orders of magnitude more troponin $\mathrm{T}$ than the control polymer [70],[83]; while Kan [62] and Li [57] have obtained an imprinting factor of ca. 7 for bovine hemoglobin with polypyrrole- and polyacrylamide-based MIPs, respectively.

Local enrichment of the protein at the electrode surface by spontaneous adsorption was also used to immobilize the template for enlarged binding capacities. Wang et al. incubated the electrode in the monomer-template mixture to allow for protein adsorption on the surface before starting the polymerization [79] (Fig. 3B). The adsorption of charged proteins can be promoted by applying an opposite conditioning potential to the electrode during incubation as described in the work of Cai et al. [68]. Ramanaviciene and Ramanavicius performed the polymerization of pyrrole with short potential pulses intermitted with longer resting periods to compensate for local depletion of monomer and protein template in the close vicinity of the electrode [84]. 


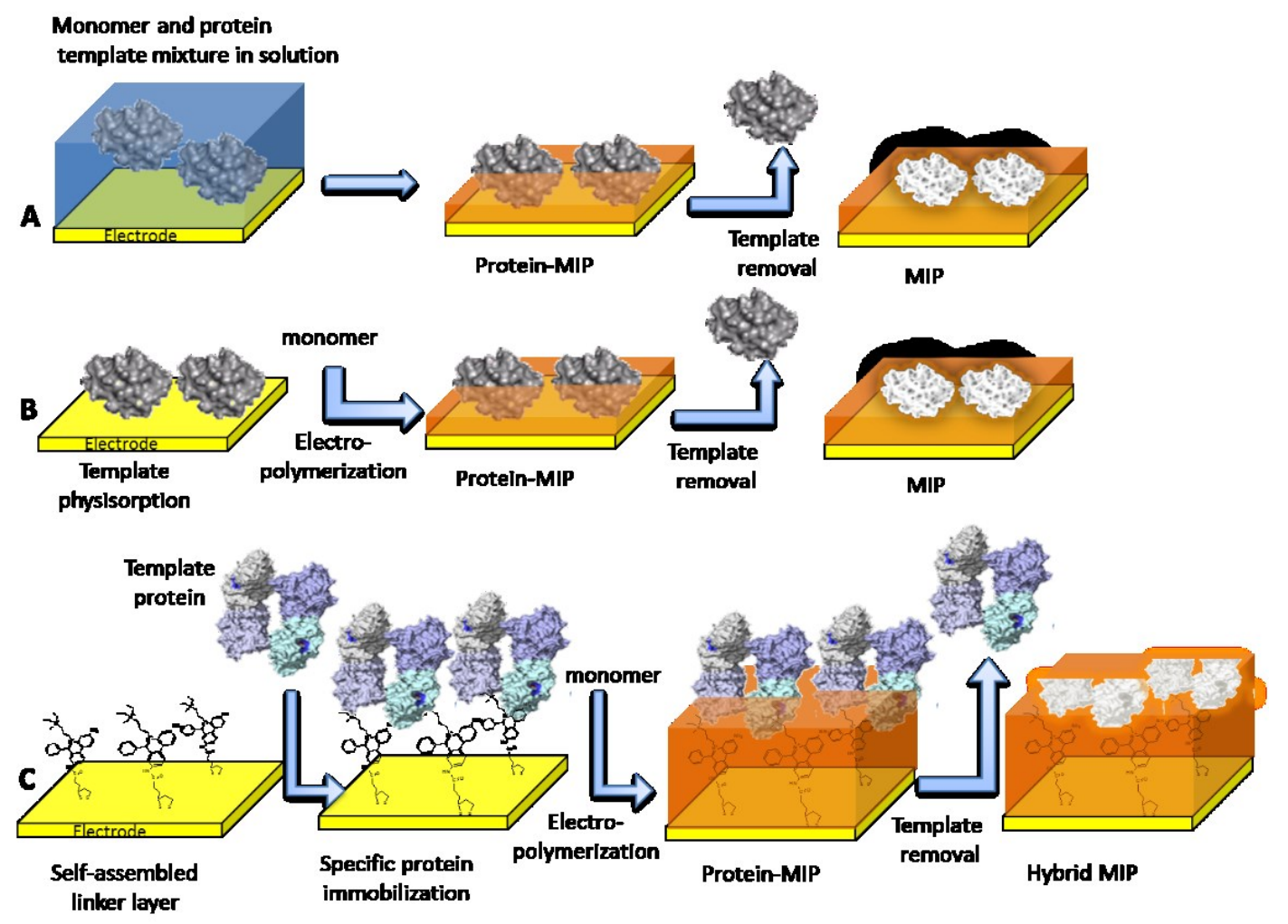

Figure 3. Various surface imprinting methodologies for the electrosynthesis of MIP films for selective recognition of proteins: electropolymerization of a mixture of protein and monomer from solution (A); preconcentration of the protein (peptide in case of epitope imprinting) on the surface of an electrode either by physisorption (B) or by using a self-assembled anchor layer for oriented immobilization of the protein (e.g. a weak inhibitor of an enzyme) (C).

The immobilization of the protein through a self-assembled anchor layer offers advantages over random immobilization or electropolymerization from a protein-monomer mixture in terms of generating uniformly accessible binding sites. Kan et al. has demonstrated [81] that covalent immobilization of the template prior to polymer deposition can significantly enhance the MIP's analytical performance: their imprinting factor reached 20 due to this modification. Scheller's group has obtained a ca. 3-fold improvement in the imprinting factor when they used immobilized template [60] instead of free protein [58] to create selective recognition sites for cytochrome $\mathrm{c}$ in a polyscopoletin film. This approach was shown to be compatible with epitope imprinting, i.e. the terminal peptide of the native protein was immobilized onto the electrode and used as template in the subsequent electropolymerization step. The concept was demonstrated by Dechtrirat et al. [66] who immobilized the surface-exposed C-terminus peptide of cytochrome c (comprising of 9 amino acids) and showed that the epitope imprinted 
polyscopoletin nanofilm could effectively rebind the native protein. An "inverse epitope-imprinting" method was proposed by Evtugyn et al. who imprinted poly(methylene green) with double-stranded DNA [85]. After template removal a short fragment of the DNA, an aptamer was rebound. Here, however, the MIP only served as a means of immobilizing the aptamer, which was in turn responsible for the recognition of the thrombin analyte.

The oriented immobilization of proteins via self-assembled anchor molecules which can reversibly bind to the protein through non-covalent bonds has been used also for the preparation of hybrid molecularly imprinted polymers. In such MIPs the binding site is generated both by the molecular imprinting process and the specific moieties of the anchoring molecule. The concept was demonstrated by using thiolated oligoethyleneglycol (OEG)/mannose monolayer self-assembled on the transducer surface to immobilize the carbohydrate binding protein, concanavalin A (ConA) [67]. Following the electropolymerization of a polyscopoletin film of comparable thickness with the protein, binding sites with enhanced binding properties were formed that comprised both the mannose moiety and the imprinted cavity. Similar methodology was implemented by Bosserdt et al. to induce oriented adsorption of cytochrome $\mathrm{c}$ by coating the electrode with an anionic self-assembled monolayer (SAM) which attracted the positively charged lysine residues of the protein neighboring its heme group [6]. Recently the enzyme acetylcholinesterase (AChE) has been "vectorially" bound via its peripheral anionic site to a propidium terminated SAM prior the deposition of an ultrathin polymer film of a ProDOT derivative [52] (Figure 3C). Propidium which is a weak inhibitor of AChE was thereby made part of the binding site in the MIP nanofilm. It was shown that in fact the binding is dominated by the propidium-protein interaction. The imprinted ProDOT film acts as a shape selective filter enabling the selective access of AChE to the propidium moiety and by that effectively suppressing interference from coexisting proteins. The selectivity was further enhanced by in-situ electrochemical detection of the enzymatic activity of AChE bound to the hybrid MIP.

The oriented protein imprinting can be achieved also by using an inert nanoparticle support for their immobilization $[54,86]$ instead of the surface of an electrode. The approach introduced by the group of Gyurcsányi used such particles to create nanostructured polymer films by assembling polystyrene nanospheres into a monolayer on the surface of an electrode, electropolymerizing PEDOT-PSS film in the voids between the spheres and then dissolving the nanospheres (Fig. 4E). This concept works best with conducting polymers alleviating the demand for ultrathin films while providing a higher binding capacity owing to the increased specific surface of the polymer. Most importantly, a significantly better discrimination could be achieved between avidin (used as target) and its analogues when the template 
was immobilized through its biotin-binding site [54], than with the same type of polymer imprinted with randomly immobilized avidin [56].
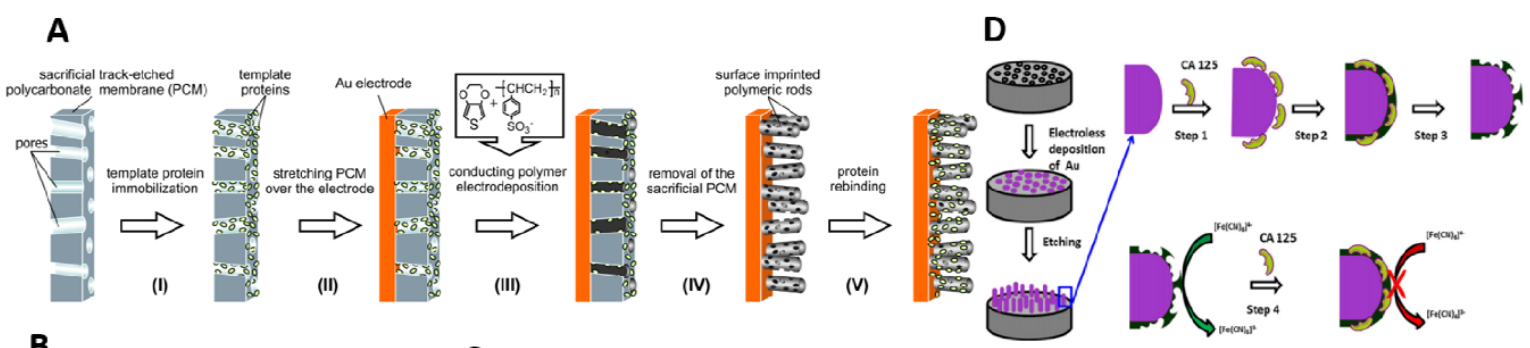

B

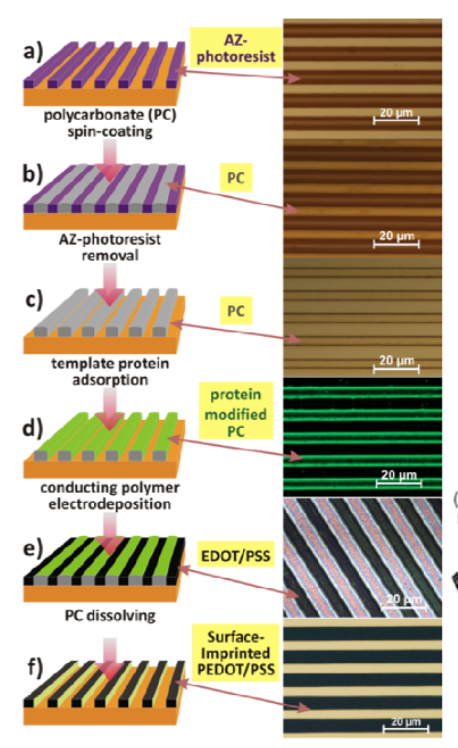

C
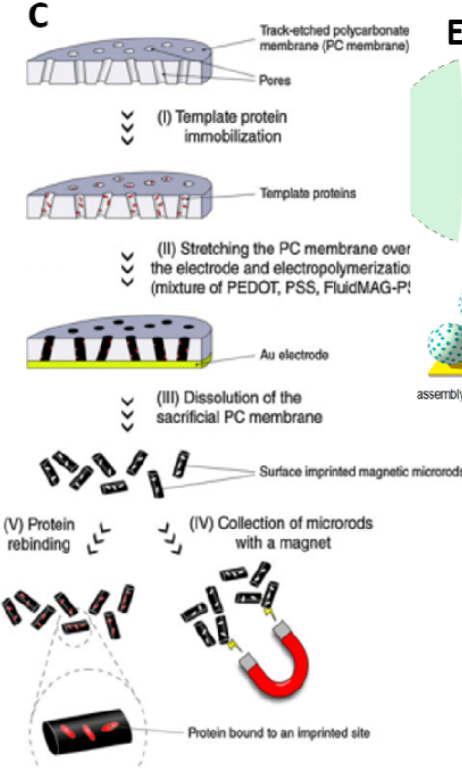

$E$

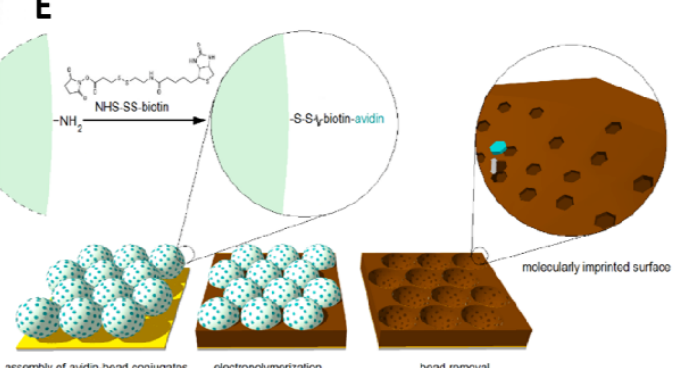

$\mathrm{F}$
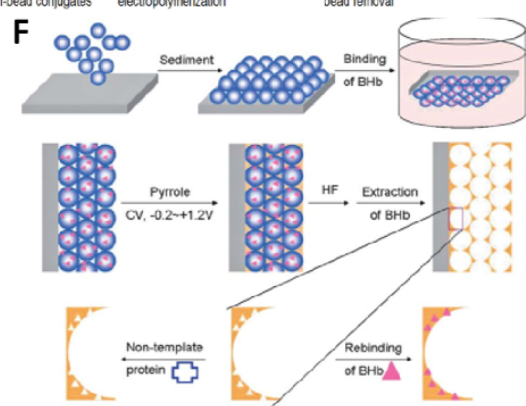

Figure 4. Micro- and nanostructuring of protein-imprinted polymers based on sacrificial materials. Template synthesis using polycarbonate-based sacrificial materials of Av-imprinted PEDOT-PSS microstructures in the form of surface confined microrods (A) (adapted with permission of ref. [5]), microbands (B) (adapted with permission of ref. [56]) and solution dispersed magnetic core particles (C) (adapted with permission of ref. [63]) as well as for protein-imprinted polyphenol coated nanoelectrode arrays (D) (adapted with permission of ref. [87]). Nanosphere lithography based on latex (E) (adapted with permission of ref. [54]) and silica beads (F) (adapted with permission of ref. [86]) as sacrificial materials for the synthesis of surface imprinted PEDOT-PSS and polypyrrole films, respectively.

The sphere lithography concept could be extended to generate surface imprinted microporous MIPs by self-assembling several sacrificial bead layers [81] (Fig. 4D) as opposed to just one [49].

The efforts towards the electrosynthesis of micro- and nanostructured MIPs with high binding capacity were supported by the use of sacrificial scaffolds, which led to the formation of nanorods [88],[87] (Fig 4D), microbands [56] (Fig. 4), and microparticles [63] (Fig. 4C). In one of the earliest attempts Menaker 
et al. [5] tightened an avidin coated track-etched polycarbonate membrane on top of a gold diskelectrode and deposited PEDOT-PSS within its pores. Afterwards, the membrane was detached from the electrode and dissolved in chloroform, liberating surface-imprinted polymer microrods that matched the size and shape of the original pores. The same concept and materials were implemented in a follow up study to enable the standard photolithographic fabrication of micropatterned surface-imprinted polymers [56] (Fig. 4B). By this methodology - compatible with large-scale fabrication - avidin-imprinted PEDOT-PSS conducting polymer microbands were prepared directly on surface plasmon resonance (SPR) chips. With the intent to enable high-throughput electrosynthesis and characterization of protein MIPs the so called microelectrospotting technique was developed by Bosserdt et al. [53]. The electrically connected spotting pin, which acted as a counter electrode, enclosed the mixture of monomer and template protein that upon contacting the surface of an electrode was in-situ electropolymerized. By using various templates and monomer mixtures surface confined polymers spots of ca. $500 \mu \mathrm{m}$ diameter were prepared on surface plasmon resonance imaging (SPRi) gold chips. It was shown that the thickness of the spots is in the low nanometer range that enables real time monitoring of template-MIP interactions by SPR. This novel format may open the route for high-throughput screening of proteinimprinted electrosynthesized MIPs given that a proper library of monomers and protein templates compatible with the microelectrospotting technology is established.

One of the main drawbacks of electrosynthetic methods is that electrochemical polymerization requires contact with an electrode and as such the fabrication of free-standing polymeric structures/particles is difficult. However, the use of sacrificial scaffolds proved to be an enabling technology also in this respect and the first report on solution dispersed electrosynthesised MIP particles used the pores of an avidin-coated track etch membrane as a microreactor to generate surface imprinted microrods [55]. To enable the recovery and handling of such nanoparticles after the removal of the sacrificial membrane, PSS modified magnetic nanoparticles were incorporated during the electrosynthesis into the PEDOT microrods. The same concept was pursued by Wang's group to prepare surface imprinted tubular microengines [64] that can actively move by bubble propulsion to capture and carry the template protein (avidin) in the sample solution. 


\subsection{Template removal}

Template removal is essential to liberate accessible binding sites for latter rebinding of the protein. The essential prerequisite for any procedure is not to alter the polymer structure in an extent that would affect the rebinding of the template. This is not as straightforward as many studies suggest and in fact the choice of the regeneration solvent is a trade-off between complete removal of the imprinted protein [56],[71] and preservation of the integrity of the binding sites [79],[87]. Accordingly, different methods were applied that range from the application of chaotropic agents to the denaturation, dissociation or lysis of the protein.

Globular proteins have been extracted by chaotropic reagents; alcohols or surfactants which induce a collapse of the tertiary structure. This method is applicable to imprints created with free or physically immobilized proteins. A wide range of treatments were reported including the use of highly acidic $[6],[84],[85]$ or basic [55] solutions and/or surfactants (sodium dodecylsulfate (SDS) [68],[89] or Tween 20 [78],[79]), sometimes at elevated temperatures [62],[6],[70]. For oligomeric proteins the dissociation into monomeric units by changing the $\mathrm{pH}$ and/or employing detergents may also be used to generate free binding sites in the MIP. Covalently immobilized proteins are removed according to the nature of the bond: a disulfide-containing crosslinker can be cleaved by reduction with mercaptoethanol [54],[81], while the imine bond is easily hydrolyzed using oxalic acid [86]. Sometimes the protein is removed together with the sacrificial support to which it was immobilized, as in the works of Menaker et al. [5], Lautner et al. [56] and Orozco et al. [64], where the polycarbonate-based support was dissolved in chloroform or dichloromethane without any further steps.

An alternative to harsh solvent extraction is the degradation of the protein target by proteolytic digestion using a protease enzyme. Proteinase K - a protease enzyme with broad cleaving specificity offers a particularly attractive alternative for protein removal under mild conditions. This approach was used for the removal of concanavalin A [67] and myoglobin [72] templates. The obtained peptides and amino acid residues, as well as the remaining protease were then washed out of the polymer with a buffer solution.

Electrochemical means have only been applied so far for the removal of small molecular weight templates, but in principle can be used also to remove protein targets. Dechtrirat et al. oxidized the thiol group tethering the template peptide chain to the electrode at a high potential [66], while Kong et al. changed the charge of the polypyrrole film by overoxidation, which thereby rejected the now identically charged template [90]. 


\subsection{Detection of the template binding}

The most important parameters characterizing the performance of MIPs are the affinity and specificity of target rebinding which determine the dynamic concentration range including the lower limit of detection and the cross reactivity. The rebinding of the target is quantified by methods which indicate directly the presence of the protein in the MIP layer and by "indirect" methods which evaluate the change in the signal of a marker molecule. Direct detection of the template protein by Raman and FTIR spectroscopy [72] offers a rather specific mean to detect the presence of the protein template in the MIP and by that to evaluate the efficiency of the template removal. In case of redox active proteins and certain enzymes the direct electron transfer[6] and the assessment of local enzymatic activity [52], respectively, offer sensitive means for the direct detection of the template protein binding to the MIP. As the signal originates in principle solely from the template bound to the MIP, nonspecific protein adsorption may interfere only in competitive manner. This is not the case for $\operatorname{SPR}[53,56,66,77,79]$ and QCM [54, 67, 81](Fig. 5D) where the signal reflects overall mass (refractive index change) of the MIP layer, which can be induced not only by the target but also by nonspecific adsorption and other type of changes of the chemical environment. It is very important to realize that such interfering effects in case of nonspecific signals does not necessarily mean that the imprinted sites lack sufficient selectivity. The reason is that it is hardly possible to imprint the whole sample exposed surface with a protein template, meaning that in fact the generated surface will be a mixture of imprinted and non-imprinted polymer (NIP). Accordingly, the NIP is expected to exhibit inherent adsorption properties of the bulk polymeric material and the lack of selectivity may easily originate from binding to the NIP fraction of the surface and not from the insufficient selectivity of the imprinted sites. A conclusive demonstration of this eventuality was provided by Dechtrirat et al. who observed a very significant interference from lysine when testing the selectivity of cytochrome c-imprinted polymers by SPR [66]. However, when injecting lysine first and then the template the signal increased roughly with the same amount as when the template was injected on a lysine-free MIP. This suggests that the lysine does not bind to surface imprinted sites, but elsewhere on the MIP, while still contributed to the SPR signal. Despite of this deficiency both SPR and QCM offer very sensitive means to evaluate the MIP-target interactions. In particular SPR imaging [56] coupled with local deposition of MIPs (Fig. 5C) having different compositions or imprinted by different templates [53] is particularly promising for high throughput optimization of MIP compositions and protein analysis. Following on the line of label-free methods the presence of the proteins in surface imprinted polymer films was successfully detected also by atomic force microscopy 
(AFM) $[52,53]$. While this method is by no means suitable for sensing application it offered clear evidence for the formation of protein imprints (cavities) (Fig. 5B) in highly conformal surface imprinted polymer layers and for the subsequent binding of proteins [52].

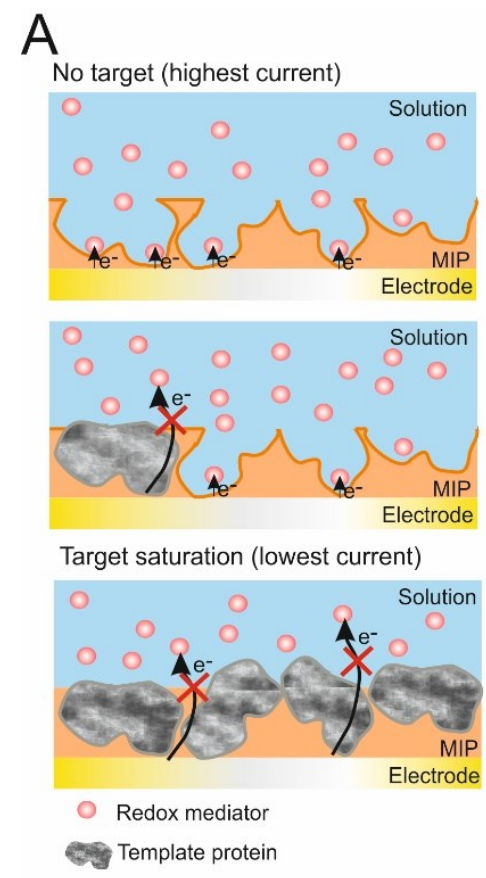

$\mathrm{B}$
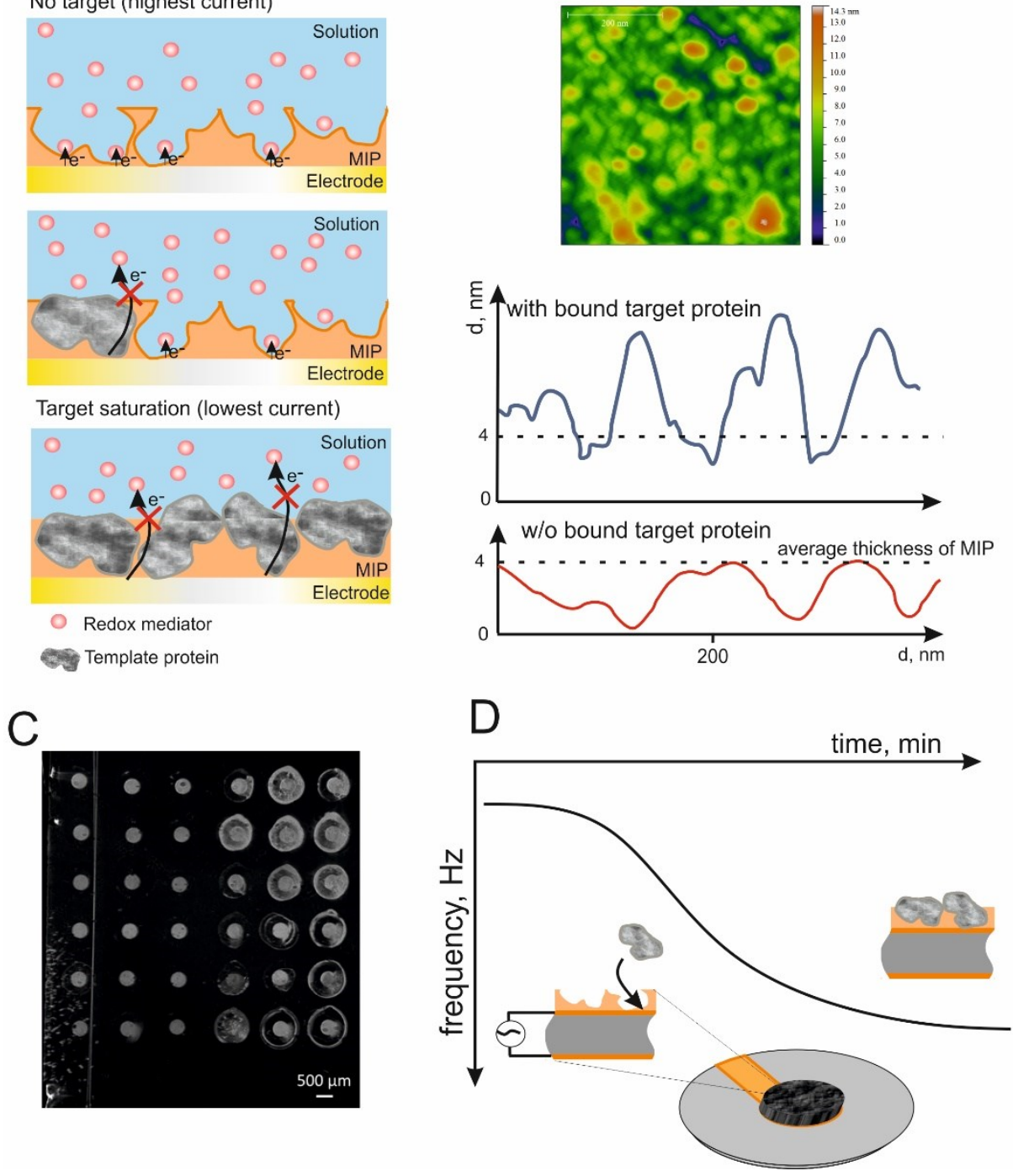

Figure 5. Representative general detection methods of the protein binding to the MIP films: (A) Electrochemical detection based on the modulation of the flux of redox mediators to the supporting electrode upon target protein binding, (B) atomic force microscopy (adapted with permission of ref. [52]), (C) surface plasmon resonance imaging (adapted with permission of ref. [53]) , (D) quartz crystal microbalance.

Labeled targets were also used for the direct assessment of template removal and rebinding. Measurement of MIP film fluorescence after interaction with a fluorescently labeled target protein 
$[61],[27,62]$ or of the enzymatic activity (HRP)[79] of enzyme labeled targets allows highly sensitive and selective quantification of rebinding. A frequently applied indirect method for the characterization of template rebinding to thin films of MIPs is based on measuring by CV [71],[86],[83] or electrochemical impedance spectroscopy [91],[89] the permeability of the polymer film for a redox marker such as ferrocyanide or ferrocenecarboxylic acid [68]. In the absence of the target protein the templated voids (binding sites) in the MIP film permit the access of the redox mediator to the underlying electrode surface while the target binding will gradually decrease the permeability of the MIP film in a concentration dependent manner, i.e., the current signal of the redox marker is diminished upon target binding (Fig. 5A). The detection scheme resembles to that of ion-channel sensors with logarithmic concentration dependence and dynamic range over several orders of magnitude[92]. This approach provides indeed a convenient procedure to follow the work flow of MIP preparation by comparing the signals of the MIP after electropolymerization, template removal and rebinding. However, it may not be fully suited for the accurate determination of binding parameters, such as binding isotherm and equilibrium constant. A major disadvantage of the method is that at low target concentrations minute decreases in the current are to be detected in a large base current. As such the fluctuation of the background current makes the uncertainty of the determinations very high in this range, especially, considering contingent swelling-shrinking of the polymer film upon change in the ionic strength and/or $\mathrm{pH}$ of the sample solution. Therefore, it is surprising that several papers describing MIPs for both low and high molecular weight targets (using the redox marker ferrocyanide) claim measuring ranges over several orders of magnitude with sub-nanomolar lower limit of detection. Many trials were made to enhance the sensitivity of the electrochemical readout of protein MIPs by using different coatings on the electrode surface prior to polymer deposition. Among these the application of graphene and carbon nanotubes stand out. Graphene, beside its excellent mechanical properties and electrical conductivity, provides a large surface that leads to an increased current response and thus better sensitivity [71],[91]. Carbon nanotubes [69],[89] are usually drop-casted onto the electrode surface prior to polymer deposition in random orientation, but Choong et al. prepared a vertically aligned array by directly growing the carbon nanotubes onto the electrode surface and electrochemically deposited an imprinted polypyrrole layer on their lateral wall [88]. Although developed with caffeine as template, this procedure is promising for the imprinting of large molecules as well because the thickness of the imprinted polymer layer can be readily tuned to match the dimensions of the template. Moreover, the capacity and the binding site density of the polymer can be controlled by varying the length and packing density of the carbon nanotubes. Indeed, later on spectacular results were reported for arrays of carbon-nanotube tips 
with an imprinted polyphenol coating that could achieve $\mathrm{pg} / \mathrm{L}$ limit of detection for ferritin and a human papillomavirus derived protein using ferrocene carboxylic acid as marker and electrochemical impedance spectroscopy for detection [68]. Microdendrites can also improve electronic transfer rates and the effective electrode area [57].

The imprinting factor IF is defined as the ratio of the signals of the MIP and NIP after rebinding of the target. It should reflect the ratio of "specific" binding of the MIP to the nonspecific binding at the NIP surface. At saturation concentrations it returns the ratio of binding capacities to the imprinted and nonimprinted polymer. As an alternative, the ratio of the slopes in the linear region of the binding curve is determined. However, for negligible nonspecific binding this method will provide nonrealistic high IF values. It is obvious that the determination of the imprinting factor is influenced by the method which was used to measure the rebinding to the MIP and NIP. For SPR and QCM the signal can be influenced by structural changes of the polymer. In this respect the evaluation of the enzymatic activity or of direct electron transfer is considerably more specific and gives a "functional" imprinting factor. The frequently used measurement of the current of a redox marker is influenced not only by the occupancy of the cavities by the target but also by the formation of "nonspecific" pores during the extraction of the template. Therefore the conditions of template removal are crucial. 
Table 1. Electrosynthesized protein MIPs

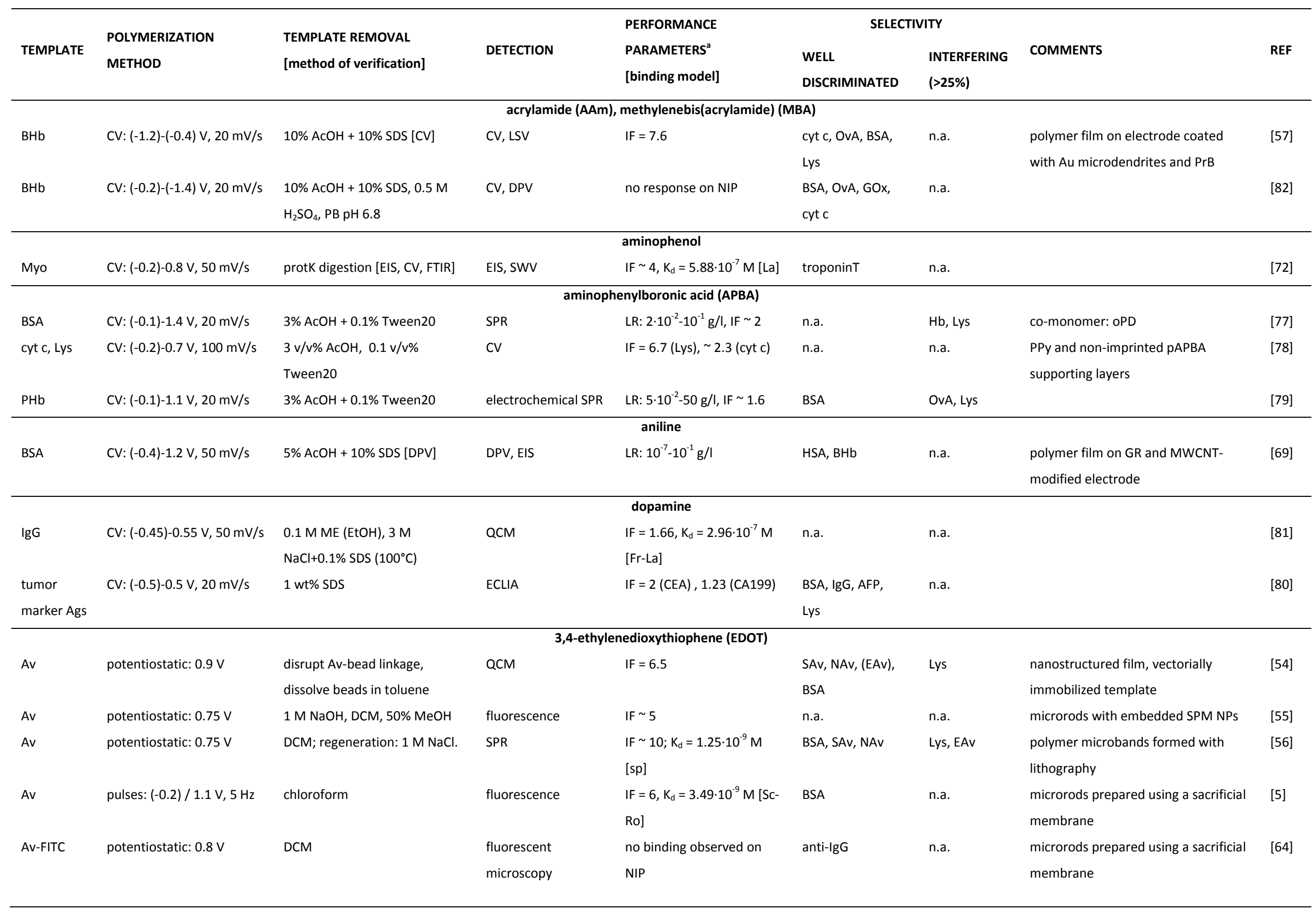




\begin{tabular}{|c|c|c|c|c|c|c|c|c|}
\hline TEMPLATE & $\begin{array}{l}\text { POLYMERIZATION } \\
\text { METHOD }\end{array}$ & $\begin{array}{l}\text { TEMPLATE REMOVAL } \\
\text { [method of verification] }\end{array}$ & DETECTION & $\begin{array}{l}\text { PERFORMANCE } \\
\text { PARAMETERS }^{\text {a }} \\
\text { [binding model] }\end{array}$ & WELL DISCRIMINATED & $\begin{array}{l}\text { INTERFERING } \\
\text { (>25\%) }\end{array}$ & COMMENTS & REF \\
\hline \multicolumn{9}{|c|}{ methylene green } \\
\hline $\begin{array}{l}\text { thrombin } \\
\text { (target) DNA } \\
\text { aptamer } \\
\text { (template) }\end{array}$ & $\begin{array}{l}C V:(-0.3)-1.3 \mathrm{~V} \\
100 \mathrm{mV} / \mathrm{s}\end{array}$ & $5 \mathrm{M} \mathrm{HCl}$ & EIS, potentiometry & $\mathrm{IF}=1.83$ & HSA & n.a. & "inverse epitope imprinting" & [85] \\
\hline \multicolumn{9}{|c|}{ phenol } \\
\hline $\begin{array}{l}\text { HFer, HPV E7 } \\
\text { protein, Cal }\end{array}$ & $\begin{array}{l}C V:(0.3 V * 30 \mathrm{~s}) \\
0-0.9 \mathrm{~V}, 50 \mathrm{mV} / \mathrm{s}\end{array}$ & $\begin{array}{l}\text { DI water or } 5 \% \mathrm{AcOH} \text { or } \\
10 \% \text { SDS }\end{array}$ & DPV, EIS & $9.8 \cdot 10^{-15} \mathrm{M}[\mathrm{Hill}]$ & $\begin{array}{l}\text { horse (apo)Fer, } \mathrm{Ca}^{2+} \text {-free } \\
\text { conformation of Cal }\end{array}$ & n.a. & arrays of carbon-nanotube tips & [68] \\
\hline $\begin{array}{l}\text { ovarian cancer } \\
\text { antigen }\end{array}$ & $\mathrm{CV}: 0-0.9 \mathrm{~V}, 50 \mathrm{mV} / \mathrm{s}$ & $\begin{array}{l}\text { DI water or } 1 \% \mathrm{AcOH}+ \\
3 \% \text { SDS [EIS] }\end{array}$ & DPV, EIS & & $\begin{array}{l}\text { HSA, human serum } \\
\text { proteins }\end{array}$ & n.a. & $\begin{array}{l}\text { polymer coating on } \\
\text { nanoelectrodes }\end{array}$ & [87] \\
\hline \multicolumn{9}{|c|}{ o-phenylenediamine (OPD) } \\
\hline troponinT & $\mathrm{CV}: 0-1.1 \mathrm{~V}, 50 \mathrm{mV} / \mathrm{s}$ & $\begin{array}{l}0.25 \mathrm{~m} \mathrm{NaOH}\left(\mathrm{EtOH}: \mathrm{H}_{2} \mathrm{O}\right. \\
2: 1)[\mathrm{CV}]\end{array}$ & CV, EIS, DPV & $\begin{array}{l}\text { LR: } 9 \cdot 10^{-9}-8 \cdot 10^{-7} \mathrm{~g} / \mathrm{l}, \mathrm{K}_{\mathrm{d}}= \\
2.4 \cdot 10^{-12} \mathrm{M}[\mathrm{sp} .+\mathrm{nsp}], \text { no }\end{array}$ & serum proteins & n.a. & & {$[70]$} \\
\hline troponinT & $\mathrm{CV}: 0-1.1 \mathrm{~V}, 50 \mathrm{mV} / \mathrm{s}$ & $\begin{array}{l}0.25 \mathrm{~m} \mathrm{NaOH}\left(\mathrm{EtOH}: \mathrm{H}_{2} \mathrm{O}\right. \\
2: 1)[\mathrm{CV}]\end{array}$ & CV, EIS, DPV & $\begin{array}{l}\text { response on NIP } \\
\text { no response on NIP, } K_{d}= \\
2.3 \cdot 10^{-13} \mathrm{M}[\mathrm{sp} .+\mathrm{nsp}]\end{array}$ & n.a. & n.a. & & [83] \\
\hline \multicolumn{9}{|c|}{ proDOT-COOH } \\
\hline AChE & $\begin{array}{l}\text { potentiostatic: } 0.75 \mathrm{~V} \\
* 5 \mathrm{~s}, 0 \mathrm{~V} * 5 \mathrm{~s}\end{array}$ & $\begin{array}{l}\text { glycine-HCl [AFM, } \\
\text { enzyme activity] }\end{array}$ & enzyme activity, AFM & $\mathrm{IF}=5.3, \mathrm{~K}_{\mathrm{d}}=4.2 \cdot 10^{-7} \mathrm{M}[\mathrm{La}]$ & BSA & urease & & {$[52]$} \\
\hline \multicolumn{9}{|c|}{ pyrrole } \\
\hline $\mathrm{BHb}$ & $\begin{array}{l}\mathrm{CV}:(-0.2)-1.2 \mathrm{~V} \\
100 \mathrm{mV} / \mathrm{s}\end{array}$ & $1 \mathrm{M} \mathrm{H}_{2} \mathrm{SO}_{4}$ [EIS] & DPV & LR: $10^{-5}-1 \mathrm{~g} / \mathrm{l}$ & BSA, HSA, Lys, BIn, ATP & n.a. & $\begin{array}{l}\text { film on electrode coated with GR } \\
\text { and IL }\end{array}$ & {$[91]$} \\
\hline $\mathrm{BHb}$ & $\begin{array}{l}\mathrm{CV}:(-0.2)-1.2 \mathrm{~V} \\
100 \mathrm{mV} / \mathrm{s}\end{array}$ & $\begin{array}{l}1 \mathrm{M} \mathrm{H}_{2} \mathrm{SO}_{4}, \mathrm{CV} \text { in } \mathrm{PBS} \\
(-0.6)-1 \mathrm{~V}\end{array}$ & DPV, EIS & $\mathrm{IF}=7.72$ & BSA & EAv, Lys & & {$[62]$} \\
\hline $\mathrm{BHb}$ & $\begin{array}{l}\mathrm{CV}:(-0.2)-1.2 \mathrm{~V} \\
100 \mathrm{mV} / \mathrm{s}\end{array}$ & $\begin{array}{l}4 \% \mathrm{HF}, 1 \mathrm{M} \text { oxalic acid } \\
{[\mathrm{DPV}]}\end{array}$ & EIS, DPV & $\mathrm{IF} \sim 20$ & BSA, EAv & Lys & nanostructured film & {$[86]$} \\
\hline BLV protein & $\begin{array}{l}\text { pulses: } 0.95 \mathrm{~V} * 1 \mathrm{~s} \\
0.35 \mathrm{~V} * 10 \mathrm{~s}\end{array}$ & $1 \mathrm{M} \mathrm{H}_{2} \mathrm{SO}_{4}[\mathrm{PA}]$ & PA, ELISA assay & $\mathrm{IF}=22$ & BSA & n.a. & & [84] \\
\hline BSA & $\begin{array}{l}\mathrm{CV}:(-0.35)-0.85 \mathrm{~V}, \\
50 \mathrm{mV} / \mathrm{s}\end{array}$ & $\begin{array}{l}5 \% \mathrm{AcOH}+10 \% \mathrm{SDS} \\
{[\mathrm{EIS}]}\end{array}$ & DPV, EIS & LR: $10^{-7}-10^{-1} \mathrm{~g} / \mathrm{l}$ & $\mathrm{HSA}, \mathrm{BHb}$ & n.a. & $\begin{array}{l}\text { polymer film on MWCNT and } \\
\text { magnetic NPs-modified electrode }\end{array}$ & [89] \\
\hline
\end{tabular}




\begin{tabular}{|c|c|c|c|c|c|c|c|c|}
\hline TEMPLATE & $\begin{array}{l}\text { POLYMERIZATION } \\
\text { METHOD }\end{array}$ & $\begin{array}{l}\text { TEMPLATE REMOVAL } \\
\text { [method of verification] }\end{array}$ & DETECTION & $\begin{array}{l}\text { PERFORMANCE PARAMETERS }^{\mathrm{a}} \\
\text { [binding model] }\end{array}$ & $\begin{array}{l}\text { SELECTIV } \\
\text { WELL } \\
\text { DISCRIMINATED }\end{array}$ & $\begin{array}{l}\text { INTERFERING } \\
\text { (>25\%) }\end{array}$ & COMMENTS & REF \\
\hline \multicolumn{9}{|c|}{ scopoletin } \\
\hline $\operatorname{con} \mathrm{A}$ & $\begin{array}{l}\text { potentiostatic: } 0.7 \mathrm{~V} \\
* 5 \mathrm{~s}, 0 \mathrm{~V} * 5 \mathrm{~s}\end{array}$ & protK digestion [fluorescence] & QCM & $\mathrm{IF}=8.6, \mathrm{~K}_{\mathrm{d}}=7.2 \cdot 10^{-10} \mathrm{M}[\mathrm{La}]$ & $\begin{array}{l}\text { BSA, Myo, RNAse, } \\
\text { lectins }\end{array}$ & n.a. & & [67] \\
\hline cyt c & $\begin{array}{l}\text { potentiostatic: } 0 \mathrm{~V}^{*} \\
15 \mathrm{~s}, 0.5 \mathrm{~V}^{*} 35 \mathrm{~s}\end{array}$ & $1 \mathrm{M} \mathrm{H}_{2} \mathrm{SO}_{4}[\mathrm{CV}]$ & $\begin{array}{l}\text { CV (DET), pseudo- } \\
\text { peroxidase activity }\end{array}$ & $\mathrm{IF}=2, \mathrm{~K}_{\mathrm{d}}=10^{-5} \mathrm{M}[\mathrm{Sc}]$ & BSA, Myo & Lys & $\begin{array}{l}\text { oriented template } \\
\text { adsorption }\end{array}$ & \\
\hline $\begin{array}{l}\text { cyt c derived } \\
\text { peptide }\end{array}$ & $\begin{array}{l}\text { potentiostatic: } 0.7 \mathrm{~V} \\
* 5 \mathrm{~s}, 0 \mathrm{~V} * 15 \mathrm{~s}\end{array}$ & $\begin{array}{l}\text { electrochemical stripping, PBS+0,1\% } \\
\text { Tween [fluorescence] }\end{array}$ & fluorescence, SPR & $\begin{array}{l}\mathrm{IF}=10 \text { (peptide), } 6 \text { (cyt c), } \mathrm{K}_{\mathrm{d}}=2.51 \cdot 10^{-6} \\
\mathrm{M} \text { (peptide), } 8.5 \cdot 10^{-6} \mathrm{M} \text { (cyt c) [Sc] }\end{array}$ & $\begin{array}{l}\text { single mismatch } \\
\text { peptide, BSA, Myo }\end{array}$ & Lys & & [66] \\
\hline ferritin & $\begin{array}{l}\text { pulses: } 0 \mathrm{~V} * 1 \mathrm{~s} \\
0.9 \mathrm{~V} * 0.1 \mathrm{~s}\end{array}$ & $5 \mathrm{mM} \mathrm{NaOH}$ injections in iSPR & iSPR & $\mathrm{IF}=13$ & cyt c, Myo & BSA, urease & $\begin{array}{l}\text { thin film confined to } \\
\text { spots }\end{array}$ & [53] \\
\hline \multicolumn{9}{|c|}{ bithiophene-derivatives } \\
\hline
\end{tabular}

${ }^{\mathrm{a}}$ LR: linear range, IF: imprinting factor (signal of MIP divided by signal of NIP), binding models: (n)sp: (non)specific binding, Sc: Scatchard, R: Rosenthal, L: Langmuir, Fr: Freundlich

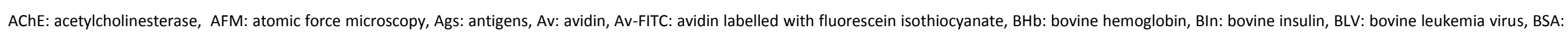

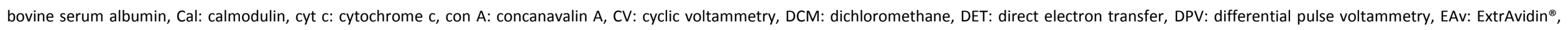

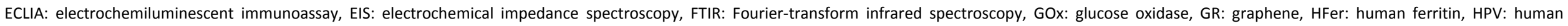

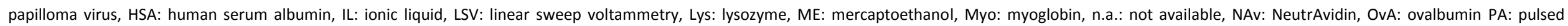

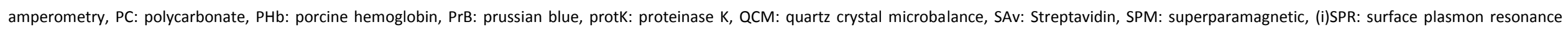
(imaging), SWV: squarewave voltammetry 


\section{Conclusions and outlook}

As compared with antibodies protein MIPs have been prepared only for a restricted spectrum of proteins starting with RNAse by Mosbach's group [25]. Almost half of the papers still use hemoglobin, serum albumins and avidin as model templates. Point-of-care detection of marker proteins for cardiac [70],[72] or tumor disease $[53,68][72],[87]$, Alzheimer's disease (AChE)[52] or virus infections is the prospective aim in the generation of electrochemically addressable MIPs. In spite of a few reports claiming close to routine applicability $[68,72]$ MIPs need still substantial improvement to overcome disturbances caused by constituents of real samples. Presently the synthesis of MIPs follows a highly empirical strategy therefore a progress is expected either from a rational design or from the association of an empirical approach with high-throughput synthesis and detection methods. The latter could accelerate the determination of the optimal MIP compositions offering high affinity and selectivity. The proof of principle of such enabling technology was already made for electrosynthesized MIPs by using microelectrospotting [53]. As an additional benefit "microfabrication" methods can drastically reduce the required amount of template making available for imprinting presently unaffordable proteins, i.e., expensive proteins or proteins available in restricted quantities, e.g. proteins produced by cell-free protein synthesis. However, it is still a question whether such high-throughput approaches can be universally applied for a wide range of monomers and proteins with distinct physico-chemical properties. With respect to the rational design the complexity of the protein-imprinted systems is a major obstacle, which may be reduced by epitope imprinting and/or the implementation of hybrid materials involving bioinspired moieties with known binding properties. Irrespective of the approach adopted the

implementation of nanomaterials and controlled oriented imprinting features as an optimal choice to increase the number and homogeneity of binding sites and by that improving the sensitivity and the selectivity of protein MIPs. The field would have also to benefit from establishing standardized testing procedure and relevant quality control criteria of the prepared protein MIPs.

\section{Acknowledgment}

The financial support of the Lendület program of the Hungarian Academy of Sciences (LP2013-63/13), ERA-Chemistry (2014, 61133; OTKA NN117637), OTKA K104724, and the German Excellence Initiative (EXC 314) is gratefully acknowledged. 


\section{References}

[1] N.W. Turner, C.W. Jeans, K.R. Brain, C.J. Allender, V. Hlady, D.W. Britt, From 3D to 2D: A review of the molecular imprinting of proteins, Biotechnol. Progr., 22 (2006) 1474-1489.

[2] D.R. Kryscio, M.Q. Fleming, N.A. Peppas, Protein Conformational Studies for Macromolecularly Imprinted Polymers, Macromol. Biosci., 12 (2012) 1137-1144.

[3] M. Glad, O. Norrlow, B. Sellergren, N. Siegbahn, K. Mosbach, Use of silane monomers for molecular imprinting and enzyme entrapment in polysiloxane-coated porous silica, J. Chromatogr., 347 (1985) 1123.

[4] H.-Y. Lin, C.-Y. Hsu, J.L. Thomas, S.-E. Wang, H.-C. Chen, T.-C. Chou, The microcontact imprinting of proteins: The effect of cross-linking monomers for lysozyme, ribonuclease A and myoglobin, Biosens. Bioelectron., 22 (2006) 534-543.

[5] A. Menaker, V. Syritski, J. Reut, A. Opik, V. Horváth, R.E. Gyurcsányi, Electrosynthesized SurfaceImprinted Conducting Polymer Microrods for Selective Protein Recognition, Adv. Mater., 21 (2009) 22712275.

[6] M. Bosserdt, N. Gajovic-Eichelman, F.W. Scheller, Modulation of direct electron transfer of cytochrome c by use of a molecularly imprinted thin film, Anal. Bioanal. Chem., 405 (2013) 6437-6444.

[7] A.L. Hillberg, M. Tabrizian, Biomolecule imprinting: Developments in mimicking dynamic natural recognition systems, Irbm, 29 (2008) 89-104.

[8] E. Verheyen, J.P. Schillemans, M. van Wijk, M.-A. Demeniex, W.E. Hennink, C.F. van Nostrum, Challenges for the effective molecular imprinting of proteins, Biomaterials, 32 (2011) 3008-3020.

[9] D.R. Kryscio, N.A. Peppas, Critical review and perspective of macromolecularly imprinted polymers, Acta Biomater., 8 (2012) 461-473.

[10] D.S. Janiak, P. Kofinas, Molecular imprinting of peptides and proteins in aqueous media, Anal. Bioanal. Chem., 389 (2007) 399-404.

[11] T. Takeuchi, T. Hishiya, Molecular imprinting of proteins emerging as a tool for protein recognition, Org. Biomol. Chem., 6 (2008) 2459-2467.

[12] Y. Lv, T. Tan, F. Svec, Molecular imprinting of proteins in polymers attached to the surface of nanomaterials for selective recognition of biomacromolecules, Biotechnol. Adv., 31 (2013) 1172-1186.

[13] M.E. Byrne, K. Park, N.A. Peppas, Molecular imprinting within hydrogels, Adv. Drug Delivery Rev., 54 (2002) 149-161.

[14] A. Bossi, F. Bonini, A.P.F. Turner, S.A. Piletsky, Molecularly imprinted polymers for the recognition of proteins: The state of the art, Biosens. Bioelectron., 22 (2007) 1131-1137.

[15] N.M. Bergmann, N.A. Peppas, Molecularly imprinted polymers with specific recognition for macromolecules and proteins, Prog. Polym. Sci., 33 (2008) 271-288.

[16] K. Yang, L. Zhang, Z. Liang, Y. Zhang, Protein-imprinted materials: rational design, application and challenges, Anal. Bioanal. Chem., 403 (2012) 2173-2183.

[17] M.J. Whitcombe, I. Chianella, L. Larcombe, S.A. Piletsky, J. Noble, R. Porter, A. Horgan, The rational development of molecularly imprinted polymer-based sensors for protein detection, Chem. Soc. Rev., 40 (2011) 1547-1571.

[18] D.E. Hansen, Recent developments in the molecular imprinting of proteins, Biomaterials, 28 (2007) 4178-4191.

[19] X. Mao, W.-A. Liang, X.-H. Peng, S.-Q. Tang, Recent Progress in Protein Imprinting Technology, Recent Pat. Nanotechnol., 4 (2010) 85-99.

[20] Y. Ge, A.P.F. Turner, Too large to fit? Recent developments in macromolecular imprinting, Trends Biotechnol., 26 (2008) 218-224. 
[21] S. Hjerten, J.L. Liao, K. Nakazato, Y. Wang, G. Zamaratskaia, H.X. Zhang, Gels mimicking antibodies in their selective recognition of proteins, Chromatographia, 44 (1997) 227-234.

[22] D. Tong, C. Hetenyi, Z. Bikadi, J.P. Gao, S. Hjerten, Some studies of the chromatographic properties of gels ('artificial antibodies/receptors') for selective adsorption of proteins, Chromatographia, 54 (2001) 7-14.

[23] A. Rachkov, N. Minoura, Recognition of oxytocin and oxytocin-related peptides in aqueous media using a molecularly imprinted polymer synthesized by the epitope approach, J. Chromatogr. A, 889 (2000) 111-118.

[24] A. Rachkov, N. Minoura, Towards molecularly imprinted polymers selective to peptides and proteins. The epitope approach, BBA-Protein Struct. M., 1544 (2001) 255-266.

[25] M. Kempe, M. Glad, K. Mosbach, An approach towards surface imprinting using the enzyme ribonuclease A, J. Mol. Recognit., 8 (1995) 35-39.

[26] N.W. Turner, B.E. Wright, V. Hlady, D.W. Britt, Formation of protein molecular imprints within Langmuir monolayers: A quartz crystal microbalance study, J. Colloid Interface Sci., 308 (2007) 71-80.

[27] H.Q. Shi, W.B. Tsai, M.D. Garrison, S. Ferrari, B.D. Ratner, Template-imprinted nanostructured surfaces for protein recognition, Nature, 398 (1999) 593-597.

[28] O. Hayden, F.L. Dickert, Selective microorganism detection with cell surface imprinted polymers, Adv. Mater., 13 (2001) 1480-1483.

[29] O. Hayden, R. Bindeus, C. Haderspock, K.J. Mann, B. Wirl, F.L. Dickert, Mass-sensitive detection of cells, viruses and enzymes with artificial receptors, Sens. Actuators, B-Chem., 91 (2003) 316-319.

[30] O. Hayden, P.A. Lieberzeit, D. Blaas, F.L. Dickert, Artificial antibodies for bioanalyte detectionsensing viruses and proteins, Adv. Funct. Mater., 16 (2006) 1269-1278.

[31] Y. Li, H.H. Yang, Q.H. You, Z.X. Zhuang, X.R. Wang, Protein recognition via surface molecularly imprinted polymer nanowires, Anal. Chem., 78 (2006) 317-320.

[32] Y. Hoshino, T. Kodama, Y. Okahata, K.J. Shea, Peptide Imprinted Polymer Nanoparticles: A Plastic Antibody, J. Am. Chem. Soc., 130 (2008) 15242-15243.

[33] A. Poma, A. Guerreiro, S. Caygill, E. Moczko, S. Piletsky, Automatic reactor for solid-phase synthesis of molecularly imprinted polymeric nanoparticles (MIP NPs) in water, RSC Adv., 4 (2014) 4203-4206.

[34] A. Poma, A. Guerreiro, M.J. Whitcombe, E.V. Piletska, A.P.F. Turner, S.A. Piletsky, Solid-Phase Synthesis of Molecularly Imprinted Polymer Nanoparticles with a Reusable Template-"Plastic Antibodies", Adv. Funct. Mater., 23 (2013) 2821-2827.

[35] S. Ambrosini, S. Beyazit, K. Haupt, B.T.S. Bui, Solid-phase synthesis of molecularly imprinted nanoparticles for protein recognition, Chem. Commun., 49 (2013) 6746-6748.

[36] A. Bossi, S.A. Piletsky, E.V. Piletska, P.G. Righetti, A.P.F. Turner, Surface-grafted molecularly imprinted polymers for protein recognition, Anal. Chem., 73 (2001) 5281-5286.

[37] F. Li, J. Li, S.S. Zhang, Molecularly imprinted polymer grafted on polysaccharide microsphere surface by the sol-gel process for protein recognition, Talanta, 74 (2008) 1247-1255.

[38] H. He, G. Fu, Y. Wang, Z. Chai, Y. Jiang, Z. Chen, Imprinting of protein over silica nanoparticles via surface graft copolymerization using low monomer concentration, Biosens. Bioelectron., 26 (2010) 760765.

[39] R.H. Schmidt, K. Mosbach, K. Haupt, A simple method for spin-coating molecularly imprinted polymer films of controlled thickness and porosity, Adv. Mater., 16 (2004) 719-722.

[40] K. Haupt, K. Noworyta, W. Kutner, Imprinted polymer-based enantioselective acoustic sensor using a quartz crystal microbalance, Anal. Commun., 36 (1999) 391-393.

[41] S.A. Piletsky, H. Matuschewski, U. Schedler, A. Wilpert, E.V. Piletska, T.A. Thiele, M. Ulbricht, Surface functionalization of porous polypropylene membranes with molecularly imprinted polymers by photograft copolymerization in water, Macromolecules, 33 (2000) 3092-3098. 
[42] C. Sulitzky, B. Ruckert, A.J. Hall, F. Lanza, K. Unger, B. Sellergren, Grafting of molecularly imprinted polymer films on silica supports containing surface-bound free radical initiators, Macromolecules, 35 (2002) 79-91.

[43] O. Norrlow, M. Glad, K. Mosbach, Acrylic polymer preparations containing recognition sites obtained by imprinting with substrates, J. Chromatogr., 299 (1984) 29-41.

[44] Y. Fuchs, A.V. Linares, A.G. Mayes, K. Haupt, O. Soppera, Ultrathin Selective Molecularly Imprinted Polymer Microdots Obtained by Evanescent Wave Photopolymerization, Chem. Mater., 23 (2011) 36453651.

[45] O.Y.F. Henry, S.A. Piletsky, D.C. Cullen, Fabrication of molecularly imprinted polymer microarray on a chip by mid-infrared laser pulse initiated polymerisation, Biosens. Bioelectron., 23 (2008) 1769-1775.

[46] P.S. Sharma, A. Pietrzyk-Le, F. D'Souza, W. Kutner, Electrochemically synthesized polymers in molecular imprinting for chemical sensing, Anal. Bioanal. Chem., 402 (2012) 3177-3204.

[47] C. Malitesta, E. Mazzotta, R.A. Picca, A. Poma, I. Chianella, S.A. Piletsky, MIP sensors - the electrochemical approach, Anal. Bioanal. Chem., 402 (2012) 1827-1846.

[48] M.C. Blanco-López, M.J. Lobo-Castañón, A.J. Miranda-Ordieres, P. Tuñón-Blanco, Electrochemical sensors based on molecularly imprinted polymers, TrAC, Trends Anal. Chem., 23 (2004) 36-48.

[49] S.A. Piletsky, A.P.F. Turner, Electrochemical Sensors Based on Molecularly Imprinted Polymers, Electroanal., 14 (2002) 317-323.

[50] M.T. Neves-Petersen, G.P. Gajula, S.B. Petersen, UV Light Effects on Proteins: From Photochemistry to Nanomedicine, in: S. Saha (Ed.) Molecular Photochemistry - Various Aspects, InTech Europe, Rijeka, 2012.

[51] W.M. Mitchell, A potential source of electrophoretic artifacts in polyacrylamide gels Biochim. Biophys. Acta, 147 (1967) 171-174.

[52] K.J. Jetzschmann, G. Jágerszki, D. Dechtrirat, A. Yarman, N. Gajovic-Eichelmann, H.-D. Gilsing, B. Schulz, R.E. Gyurcsányi, F.W. Scheller, Vectorially Imprinted Hybrid Nanofilm for Acetylcholinesterase Recognition, Adv. Funct. Mater., (2015).

[53] M. Bosserdt, J. Erdőssy, G. Lautner, J. Witt, K. Köhler, N. Gajovic-Eichelmann, A. Yarman, G. Wittstock, F.W. Scheller, R.E. Gyurcsányi, Microelectrospotting as a new method for electrosynthesis of surface-imprinted polymer microarrays for protein recognition, Biosens. Bioelectron., 73 (2015) 123-129. [54] J. Bognár, J. Szűcs, Z. Dorkó, V. Horváth, R.E. Gyurcsányi, Nanosphere Lithography as a Versatile Method to Generate Surface-Imprinted Polymer Films for Selective Protein Recognition, Adv. Funct. Mater., 23 (2013) 4703-4709.

[55] G. Ceolin, A. Orban, V. Kocsis, R.E. Gyurcsanyi, I. Kezsmarki, V. Horvath, Electrochemical template synthesis of protein-imprinted magnetic polymer microrods, Journal of Materials Science, 48 (2013) 5209-5218.

[56] G. Lautner, J. Kaev, J. Reut, A. Oepik, J. Rappich, V. Syritski, R.E. Gyurcsányi, Selective Artificial Receptors Based on Micropatterned Surface-Imprinted Polymers for Label-Free Detection of Proteins by SPR Imaging, Adv. Funct. Mater., 21 (2011) 591-597.

[57] Y. Li, Y. Li, M. Hong, Q. Bin, Z. Lin, Z. Lin, Z. Cai, G. Chen, Highly sensitive protein molecularly imprinted electro-chemical sensor based on gold microdendrites electrode and prussian blue mediated amplification, Biosens. Bioelectron., 42 (2013) 612-617.

[58] Y. Liu, X.W. Shi, E. Kim, L.M. Robinson, C.K. Nye, R. Ghodssi, G.W. Rubloff, W.E. Bentley, G.F. Payne, Chitosan to electroaddress biological components in lab-on-a-chip devices, Carbohydr. Polym., 84 (2011) 704-708.

[59] R.E. Gyurcsányi, A. Cristalli, G. Nagy, L. Nagy, C. Corder, B.D. Pendley, S. Ufer, H.T. Nagle, M.R. Neuman, E. Lindner, Analytical performance characteristics of thin and thick film amperometric microcells, Fresenius J. Anal. Chem., 369 (2001) 286-294. 
[60] A. Ramanavicius, A. Ramanaviciene, A. Malinauskas, Electrochemical sensors based on conducting polymer- polypyrrole, Electrochim. Acta, 51 (2006) 6025-6037.

[61] A. Ramanavicius, Y. Oztekin, A. Ramanaviciene, Electrochemical formation of polypyrrole-based layer for immunosensor design, Sens. Actuators, B-Chem., 197 (2014) 237-243.

[62] X. Kan, Z. Xing, A. Zhu, Z. Zhao, G. Xu, C. Li, H. Zhou, Molecularly imprinted polymers based electrochemical sensor for bovine hemoglobin recognition, Sens. Actuators, B-Chem., 168 (2012) 395401.

[63] G. Ceolin, A. Orbán, V. Kocsis, R.E. Gyurcsányi, I. Kézsmárki, V. Horváth, Electrochemical template synthesis of protein-imprinted magnetic polymer microrods, J. Mater. Sci., 48 (2013) 5209-5218.

[64] J. Orozco, A. Cortes, G.Z. Cheng, S. Sattayasamitsathit, W. Gao, X.M. Feng, Y.F. Shen, J. Wang, Molecularly Imprinted Polymer-Based Catalytic Micromotors for Selective Protein Transport, J. Am. Chem. Soc., 135 (2013) 5336-5339.

[65] N. Gajovich-Eichelmann, Directed immobilization of nucleic acids at ultramicroelectrodes using a novel electro-deposited polymer, Biosens. Bioelectron., 19 (2003) 417-422.

[66] D. Dechtrirat, K.J. Jetzschmann, W.F.M. Stocklein, F.W. Scheller, N. Gajovic-Eichelmann, Protein Rebinding to a Surface-Confined Imprint, Adv. Funct. Mater., 22 (2012) 5231-5237.

[67] D. Dechtrirat, N. Gajovic-Eichelmann, F.F. Bier, F.W. Scheller, Hybrid Material for Protein Sensing Based on Electrosynthesized MIP on a Mannose Terminated Self-Assembled Monolayer, Adv. Funct. Mater., 24 (2014) 2233-2239.

[68] D. Cai, L. Ren, H.Z. Zhao, C.J. Xu, L. Zhang, Y. Yu, H.Z. Wang, Y.C. Lan, M.F. Roberts, J.H. Chuang, M.J. Naughton, Z.F. Ren, T.C. Chiles, A molecular-imprint nanosensor for ultrasensitive detection of proteins, Nat. Nanotechnol., 5 (2010) 597-601.

[69] H.-J. Chen, Z.-H. Zhang, D. Xie, R. Cai, X. Chen, Y.-N. Liu, S.-Z. Yao, Surface-Imprinting Sensor Based on Carbon Nanotubes/Graphene Composite for Determination of Bovine Serum Albumin, Electroanal., 24 (2012) 2109-2116.

[70] N. Karimian, M. Vagin, M.H.A. Zavar, M. Chamsaz, A.P.F. Turner, A. Tiwari, An ultrasensitive molecularly-imprinted human cardiac troponin sensor, Biosens. Bioelectron., 50 (2013) 492-498.

[71] X.D. Wang, J. Dong, H.M. Ming, S.Y. Ai, Sensing of glycoprotein via a biomimetic sensor based on molecularly imprinted polymers and graphene-Au nanoparticles, Analyst, 138 (2013) 1219-1225.

[72] F.T.C. Moreira, S. Sharma, R.A.F. Dutra, J.P.C. Noronha, A.E.G. Cass, M.G.F. Sales, Protein-responsive polymers for point-of-care detection of cardiac biomarker, Sens. Actuators, B-Chem., 196 (2014) 123132.

[73] B. Deore, M.S. Freund, Saccharide imprinting of poly(aniline boronic acid) in the presence of fluoride, Analyst, 128 (2003) 803-806.

[74] S.Q. Liu, L. Bakovic, A.C. Chen, Specific binding of glycoproteins with poly(aniline boronic acid) thin film, J. Electroanal. Chem., 591 (2006) 210-216.

[75] M. Glad, S. Ohlson, L. Hansson, M.O. Mánsson, K. Mosbach, High-performance liquid affinity chromatography of nucleosides, nucleotides and carbohydrates with boronic acid-substituted microparticulate silica, J. Chromatogr. A, 200 (1980) 254-260.

[76] S.S. Wang, J. Ye, Z. Bie, Z. Liu, Affinity-tunable specific recognition of glycoproteins via boronate affinity-based controllable oriented surface imprinting, Chem. Sci., 5 (2014) 1135-1140.

[77] Y. Wang, T.X. Wei, Surface plasmon resonance sensor chips for the recognition of bovine serum albumin via electropolymerized molecularly imprinted polymers, Chin. Chem. Lett., 24 (2013) 813-816.

[78] J. Rick, T.-C. Chou, Using protein templates to direct the formation of thin-film polymer surfaces, Biosens. Bioelectron., 22 (2006) 544-549.

[79] Y. Wang, Q.W. Zhang, Y.M. Ren, L.J. Jing, T.X. Wet, Molecularly Imprinted Polymer Thin Film Based Surface Plasmon Resonance Sensor to Detect Hemoglobin, Chem. Res. Chin. Univ., 30 (2014) 42-48. 
[80] X. Feng, N. Gan, J. Zhou, T. Li, Y. Cao, F. Hu, H. Yu, Q. Jiang, A novel dual-template molecularly imprinted electrochemiluminescence immunosensor array using Ru(bpy)(3)(2+)-Silica@Poly-L-lysine-Au composite nanoparticles as labels for near-simultaneous detection of tumor markers, Electrochim. Acta, 139 (2014) 127-136.

[81] A. Tretjakov, V. Syritski, J. Reut, R. Boroznjak, O. Volobujeva, A. Opik, Surface molecularly imprinted polydopamine films for recognition of immunoglobulin G, Microchim. Acta, 180 (2013) 1433-1442.

[82] S. Wu, W. Tan, H. Xu, Protein molecularly imprinted polyacrylamide membrane: for hemoglobin sensing, Analyst, 135 (2010) 2523-2527.

[83] N. Karimian, A.P.F. Turner, A. Tiwari, Electrochemical evaluation of troponin T imprinted polymer receptor, Biosens. Bioelectron., 59 (2014) 160-165.

[84] A. Ramanaviciene, A. Ramanavicius, Molecularly imprinted polypyrrole-based synthetic receptor for direct detection of bovine leukemia virus glycoproteins, Biosens. Bioelectron., 20 (2004) 1076-1082.

[85] G. Evtugyn, A. Porfireva, A. Ivanov, O. Konovalova, T. Hianik, Molecularly Imprinted Polymerized Methylene Green as a Platform for Electrochemical Sensing of Aptamer-Thrombin Interactions, Electroanal., 21 (2009) 1272-1277.

[86] L. Li, L.L. Yang, Z.L. Xing, X.J. Lu, X.W. Kan, Surface molecularly imprinted polymers-based electrochemical sensor for bovine hemoglobin recognition, Analyst, 138 (2013) 6962-6968.

[87] S. Viswanathan, C. Rani, S. Ribeiro, C. Delerue-Matos, Molecular imprinted nanoelectrodes for ultra sensitive detection of ovarian cancer marker, Biosens. Bioelectron., 33 (2012) 179-183.

[88] C.-L. Choong, J.S. Bendall, W.I. Milne, Carbon nanotube array: A new MIP platform, Biosens. Bioelectron., 25 (2009) 652-656.

[89] H.-J. Chen, Z.-H. Zhang, L.-J. Luo, S.-Z. Yao, Surface-imprinted chitosan-coated magnetic nanoparticles modified multi-walled carbon nanotubes biosensor for detection of bovine serum albumin, Sens. Actuators, B-Chem., 163 (2012) 76-83.

[90] Y. Kong, W. Zhao, S. Yao, J. Xu, W. Wang, Z. Chen, Molecularly Imprinted Polypyrrole Prepared by Electrodeposition for the Selective Recognition of Tryptophan Enantiomers, J. Appl. Polym. Sci., 115 (2010) 1952-1957.

[91] Z.H. Wang, F. Li, J.F. Xia, L. Xia, F.F. Zhang, S. Bi, G.Y. Shi, Y.Z. Xia, J.Q. Liu, Y.H. Li, L.H. Xia, An ionic liquid-modified graphene based molecular imprinting electrochemical sensor for sensitive detection of bovine hemoglobin, Biosens. Bioelectron., 61 (2014) 391-396.

[92] Y. Umezawa, H. Aoki, Ion channel sensors based on artificial receptors, Anal. Chem., 76 (2004) 320A326A.

[93] M. Cieplak, K. Szwabinska, M. Sosnowska, K.C.C. Bikram, P. Borowicz, K. Noworyta, F. D'Souza, W. Kutner, Selective electrochemical sensing of human serum albumin by semi-covalent molecular imprinting, Biosens. Bioelectron., 74 (2015) 960-966. 